\title{
DIGESTI LOGAM ZINK (Zn) DALAM SEDIMEN ESTUARIA SUNGAI PALU DENGAN KOMBINASI ASAM MINERAL
}

\author{
Digestion of Zinc Metal (Zn) in the Estuarine Sediments of Palu River with the Combination of \\ Mineral Acids
}

\author{
*Stefhanny Galib, Irwan Said, dan Mery Napitupulu \\ Pendidikan Kimia/FKIP - Universitas Tadulako, Palu - Indonesia 94118 \\ Received 22 September 2017, Revised 23 October 2017, Accepted 24 November 2017
}

\begin{abstract}
The research was conducted to determine the digestion power is highest of $\mathrm{Zn}$ metal with combination of mineral acids in the estuarine sediments of Palu River samples. Zn metal concentrations in the sediments was analysed by atomic absorption spectroscopy $(A A S)$ at a wavelength of $231.9 \mathrm{~nm}$. The results showed that water content ranged between $30.36 \%-37.18 \%$, ash content ranged from $52.40-68.76 \%$, and biomass content ranged from $0.88-10.42 \%$. Analysis of $A A S$ showed the significant average of $Z n$ metal on a combination of mineral acids $\mathrm{HNO}_{3}-\mathrm{H}_{2} \mathrm{SO}(1: 1)$ was $289.95 \pm 182.49 \mathrm{mg} / \mathrm{kg}$, and on acombination of mineral acids $\mathrm{HNO}_{3}-$ $\mathrm{HCl}(1: 3)$ was $669.18 \pm 447.2 \mathrm{mg} / \mathrm{kg}$. While calculation results of the relative standard deviation values were $25.35 \%$ for the combunation of mineral acids $\mathrm{HNO}_{3}-\mathrm{H}_{2} \mathrm{SO}_{4}(1: 1)$, and 22\% for the combination of mineral acids $\mathrm{HNO}_{3}-\mathrm{HCl}$ (1:3). The combination of mineral acids having the highest digestion to the $\mathrm{Zn}$ metal in the estuarine sediments of Palu River was a combination of mineral acids $\mathrm{HNO}_{3}-\mathrm{HCl}(1: 3)$.
\end{abstract}

Keywords: Digestion, Zink (Zn), Sediment, Mineral Acid

\section{Pendahuluan}

Lingkungan perairan khususnya kawasan estuaria merupakan jalur bagi pergerakan sedimen dari darat dan laut. Sungai Palu yang membelah wilayah Kota Palu hampir tidak pernah lepas dari berbagai kegiatan dan aktivitas manusia, baik sebagai tempat penambangan pasir untuk kebutuhan konstruksi bagi masyarakat kota Palu, maupun sebagai tempat pembuangan langsung limbah rumah tangga serta limbah domestik yang berupa limbah pertanian, rumah sakit dan industri yang berpotensi sebagai sumber masuknya logam berat pada kawasan estuaria sungai Palu.

Logam berat yang terakumulasi di perairan dapat mengkontaminasi manusia melalui rantai makanan. Logam berat dalam kadar yang rendah dibutuhkan oleh organisme perairan, namun dalam kadar tinggi yang melebihi nilai ambang batas dapat bersifat racun dan menganggu kesehatan (Edward, 2014). Logam berat yang dianalisis pada penelitian ini adalah logam Zn yang banyak berasal dari limbah industri rotan yang banyak terdapat di daerah kota Palu. Logam ini diperkirakan banyak terdapat dalam sedimen estuaria yang merupakan substrat dasar dari perairan yang menjadi tempat akumulasi logamlogam berat.

Konsentrasi logam $\mathrm{Zn}$ dapat ditentukan dengan menggunakan suatu teknik preparasi yang tepat karena proses preparasi sampel sangat menentukan

*Correspondence

Stefhanny Galib

Program Studi Pendidikan Kimia, Fakultas Keguruan dan Ilmu Pendidikan, Universitas Tadulako

e-mail: galib.stefhanny@gmail.com

Published by Universitas Tadulako 2017 keberhasilan suatu analisis. Preparasi sampel untuk memperoleh konsentrasi logam Zn dilakukan melalui proses digesti. Pada proses ini umumnya sampel dilarutkan dalam senyawa asam mineral tunggal atau kombinasi dari beberapa senyawa asam mineral sebagai agen pendigesti.

Menurut Twyman (2005) penggunaan kombinasi asam sebagai agen digesti lebih menguntungkan jika dibandingkan dengan asam tunggal karena asam-asam tertentu dapat melarutkan beberapa logam dan senyawa-senyawa tertentu. Kombinasi asam akan memberikan kekuatan asam yang lebih baik khususnya dalam melarutkan logam-logam yang terdapat dalam sampel organik dan mendegradasi sampel organik. Kombinasi antara asam yang satu dengan yang lain akan memberikan karakteristik kemampuan digesti yang berbeda-beda pula.

Penentuan konsentrasi logam berat yang telah dilakukan oleh beberapa peneliti dengan menggunakan kombinasi dari asam mineral sebagai agen pendigesti yaitu Öztürk, dkk., (2009) menggunakan campuran $\mathrm{HNO}_{3}$ dan $\mathrm{H}_{2} \mathrm{SO}_{4}$ (1:1) dan dipanaskan pada suhu $105^{\circ} \mathrm{C}$. Selain itu, Ratnasari, dkk., (2013) menggunakan campuran $\mathrm{HNO}_{3}$ dan $\mathrm{HCl}(1: 3)$ dan dipanaskan pada suhu $140{ }^{\circ} \mathrm{C}$.

Tulisan ini dimaksudkan untuk mengurai proses digesti dengan kombinasi asam mineral mana yang memiliki daya digesti paling tinggi pada logam $\mathrm{Zn}$ dalam sampel sedimen estuaria Sungai Palu.

\section{Metode}

Alat-alat yang digunakan pada penelitian ini adalah spektofotometri serapan atom (SSA) tipe 
GBC Avanta, lampu katoda untuk logam Zn, neraca analitik, tanur (furnace), oven, pemanas listrik (hotplate), desikator, cawan tanur, batu didih, wisestir, magnetic stirrer, $\mathrm{pH}$ meter, kertas saring serta alat-alat gelas yang umum digunakan dalam analisis kimia. Sedangkan bahan-bahan yang digunakan pada penelitian ini adalah sampel sedimen, larutan asam mineral pekat $\mathrm{HNO}_{3}$ (Merck), $\mathrm{HCl}$ (Merck), $\mathrm{H}_{2} \mathrm{SO}_{4}$ (Merck), larutan standar Zn 1000 ppm (Merck) dan akuades.

\section{Prosedur Analisis}

Tahapan-tahapan dalam prosedur untuk pengujian-pengujian berikut dikutip dari Fismawati, (2010).

\section{Penentuan kadar air, kadar abu dan kadar biomassa}

Sampel sedimen yang telah diambil ditimbang sebanyak $50 \mathrm{~g}$, lalu dimasukkan kedalam oven pada suhu terkontrol $\left(105^{\circ} \mathrm{C}\right)$ selama 60 menit kemudian ditimbang.Pemanasan dilakukan berulang hingga diperoleh berat konstan.

Sampel sedimen kering kemudian diabukan dalam tanur pada suhu $800^{\circ} \mathrm{C}$ selama 5 jam. Abu yang diperoleh kemudian ditimbang lalu ditentukan kadar abu dan kadar biomassanya.

\section{Digesti dengan kombinasi asam mineral}

Digesti dengan kombinasi asam mineral $\mathrm{HNO}_{3-}$ $\mathrm{H}_{2} \mathrm{SO}_{4}(1: 1)$

Sampel kering yang sudah diabukan ditimbang sebanyak $1 \mathrm{~g}$, ditambahkan dengan $10 \mathrm{~mL}$ larutan $\mathrm{HNO}_{3}$ pekat lalu ditambahkan lagi dengan $10 \mathrm{~mL}$ larutan $\mathrm{H}_{2} \mathrm{SO}_{4}$ pekat dan dipanaskan diatas pemanas listrik sampai hampir kering. Setelah itu ditambahkan lagi dengan $20 \mathrm{~mL}$ larutan $\mathrm{HNO}_{3}$ $0,1 \mathrm{M}$ dan $20 \mathrm{~mL}$ larutan $\mathrm{H}_{2} \mathrm{SO}_{4} \quad 0,1 \mathrm{M}$ lalu dipanaskan sampai mendidih dan setelah campuran dingin, kemudian dishaker selama 1 jam. Campuran disaring sebanyak 3 kali lalu filtrat dimasukkan kedalam labu ukur $50 \mathrm{~mL}$ dan ditambahkan akuades sampai tanda batas.

Digesti dengan kombinasi asam mineral $\mathrm{HNO}_{3-}$ $\mathrm{HCl}(1: 3)$

Sampel kering yang sudah diabukan ditimbang sebanyak $1 \mathrm{~g}$, ditambahkan dengan $5 \mathrm{~mL}$ larutan $\mathrm{HNO}_{3}$ pekat lalu ditambahkan lagi dengan $15 \mathrm{~mL}$ larutan $\mathrm{HCl}$ pekat dan dipanaskan diatas pemanas listrik sampai hampir kering. Setelah itu ditambahkan lagi dengan $10 \mathrm{~mL}$ larutan $\mathrm{HNO}_{3}$ $0,1 \mathrm{M}$ dan $30 \mathrm{~mL}$ larutan $\mathrm{HCl} 0,1 \mathrm{M}$ lalu dipanaskan sampai mendidih dan setelah campuran dingin, kemudian dishaker selama 1 jam. Campuran disaring sebanyak 3 kali lalu filtrat dimasukkan kedalam labu ukur $50 \mathrm{~mL}$ dan ditambahkan akuades sampai tanda batas.

\section{Pembuatan larutan standar $Z n 100$ ppm}

Dari larutan induk Zn 1000 ppm diambil 10 mL kemudian diencerkan dalam labu ukur 100 $\mathrm{mL}$ dan ditambahkan akuades sampai tanda batas.
Kemudian dibuat deret kerja larutan standar dengan cara diencerkan secara bertahap yaitu: 0,0 ; 0,$5 ; 1,0 ; 2,0 ; 3,0 ; 4,0$ dan 5,0 ppm.

Konsentrasi logam $\mathrm{Zn}$ dalam larutan sampel ditentukan dengan menggunakan alat Spektrofotometri serapan atom (SSA) yang menggunakan lampu katoda khusus untuk logam $\mathrm{Zn}$ sebagai sumber sinar. Kemudian diukur serapan dari larutan sampel pada panjang gelombang 213,9 $\mathrm{nm}$ untuk logam $\mathrm{Zn}$ dan tipe nyala AA (udara-asetilen) (Khopkar, 1990).

\section{Hasil Dan Pembahasan}

\section{Karakteristik lokasi pengambilan sampel}

Berdasarkan hasil pengamatan pada lokasi pengambilan sampel sedimen di kawasan estuaria Sungai Palu, dapat dikemukakan karakteristik dari masing-masing lokasi pengambilan sampel dalam Tabel 1.

Tabel 1.Karakteristik masing-masing lokasi pengambilan sampel.

\begin{tabular}{|c|c|c|c|c|}
\hline \multirow[t]{2}{*}{ No } & \multirow{2}{*}{$\begin{array}{c}\text { Karakterist } \\
\text { ik }\end{array}$} & \multicolumn{3}{|c|}{ Lokasi } \\
\hline & & $\mathrm{A}$ & B & $\mathrm{C}$ \\
\hline 1. & $\begin{array}{c}\text { Aktivitas } \\
\text { sekitar } \\
\text { lokasi }\end{array}$ & $\begin{array}{l}\text { Pelayaran, } \\
\text { rekreasi, } \\
\text { pemukima } \\
\text { n }\end{array}$ & $\begin{array}{c}\text { Pelayara } \\
\text { n, } \\
\text { rekreasi, } \\
\text { estuaria } \\
\text { (muara } \\
\text { sungai) }\end{array}$ & $\begin{array}{c}\text { Pelayaran, } \\
\text { rekreasi, } \\
\text { pemukima } \\
\text { n }\end{array}$ \\
\hline 2. & $\begin{array}{c}\text { Tipe } \\
\text { sedimen }\end{array}$ & $\begin{array}{l}\text { Lumpur } \\
\text { berpasir }\end{array}$ & Lumpur & Pasir halus \\
\hline 3. & $\begin{array}{c}\text { Nilai } \\
\text { parameter } \\
\text { kualitas air } \\
\mathrm{pH} \\
\text { Suhu }\left({ }^{\circ} \mathrm{C}\right)\end{array}$ & $\begin{array}{c}7,66 \\
29,50\end{array}$ & $\begin{array}{c}7,83 \\
30,20\end{array}$ & $\begin{array}{c}7,54 \\
29,90\end{array}$ \\
\hline
\end{tabular}

Berdasarkan hasil pengukuran suhu pada saat sampling berkisar antara $29,5^{\circ} \mathrm{C}-30,2^{\circ} \mathrm{C}$. Suhu tertinggi terdapat pada lokasi $\mathrm{B}$, sedangkan suhu terendah terdapat pada lokasi A. Menurut Darmono (2008) semakin tinggi suhu air, daya toksisitas logam semakin meningkat, sebaliknya semakin rendah suhu air maka daya toksisitas logam juga semakin menurun.

Hasil pengukuran nilai $\mathrm{pH}$ perairan di kawasan estuaria Sungai Palu berkisar antara 7,54-7,83. Nilai $\mathrm{pH}$ tertinggi terdapat pada lokasi $\mathrm{B}$ dan nilai $\mathrm{pH}$ terendah terdapat pada lokasi C. Nilai $\mathrm{pH}$ perairan memiliki hubungan yang erat dengan sifat kelarutan logam berat. Secara umum logam berat akan meningkat toksisitasnya pada $\mathrm{pH}$ rendah, sedangkan pada $\mathrm{pH}$ tinggi logam berat akan mengalami pengendapan (Sarjono, 2009).

\section{Kadar air, kadar abu dan kadar biomassa}

Hasil perhitungan kadar air, kadar abu dan kadar biomassa dalam sampel pada masing-masing lokasi dapat dilihat dalam Tabel 2.

Berdasarkan Tabel 2 terlihat bahwa kadar air sampel sedimen dari masing-masing lokasi pengambilan sampel berkisar antara 30,36\%- 
37,18\%. Kadar air tertinggi terdapat pada lokasi B yang memiliki partikel sedimen berupa lumpur, sedangkan kadar air terendah terdapat pada lokasi C yang memiliki partikel sedimen berupa pasir halus. Besarnya kadar air pada sedimen dipengaruhi oleh ukuran partikel sedimen. Semakin kecil partikel sedimen, kadar air yang diperoleh semakin besar karena luas permukaan sedimen semakin besar pula, yang menyebabkan semakin banyaknya ikatan yang terbentuk antara patikel sedimen dengan molekul air (Fismawati, 2010).

Tabel 2.Kadar air, kadar abu dan kadar biomassa dari masing-masing lokasi pengambilan sampel.

\begin{tabular}{lllll}
\hline No. & $\begin{array}{l}\text { Kode } \\
\text { sampel }\end{array}$ & $\begin{array}{l}\text { Kadar } \\
\text { air (\%) }\end{array}$ & $\begin{array}{l}\text { Kadar } \\
\text { abu (\%) }\end{array}$ & $\begin{array}{l}\text { Kadar } \\
\text { biomassa } \\
(\%)\end{array}$ \\
\hline 1. & A & 33,20 & 65,08 & 1,72 \\
2. & B & 37,18 & 52,40 & 10,42 \\
3. & C & 30,36 & 68,76 & 0,88 \\
\hline
\end{tabular}

Kadar abu sampel sedimen dari masing-masing lokasi pengambilan sampel berkisar antara 52,40\% - 68,76\%. Kadar abu tertinggi terdapat pada lokasi $\mathrm{C}$, sedangkan kadar abu terendah terdapat pada lokasi B. Kadar abu merupakan ukuran bagi material yang tidak terbakar. Besarnya kadar abu pada sedimen dipengaruhi oleh ukuran partikel sedimen. Semakin besar partikel sedimen maka kadar abu yang diperoleh semakin besar pula karena akan semakin sedikit sedimen yang terbakar menjadi abu (Andrean, 2012).

Kadar biomassa sampel sedimen dari masingmasing lokasi pengambilan sampel berkisar antara 0,88-10,42\%. Kadar biomassa tertinggi terdapat pada lokasi B yang memiliki ukuran partikel sedimen paling kecil dengan luas permukaan yang besar sehingga memungkinkan keberadaan organisme organik dalam sedimen semakin banyak sedangkan kadar biomassa terendah terdapat pada lokasi C yang memiliki ukuran partikel sedimen lebih besar dengan luas permukaan yang kecil (Fismawati, 2010).

\section{Konsentrasi logam zink ( $Z n)$}

Untuk mengetahui konsentrasi logam $\mathrm{Zn}$ maka dilakukan proses digesti yang dilakukan melalui perombakan organik logam didalam sampel sedimen menjadi logam-logam anorganik dengan cara pengabuan sampel dalam furnace dan memerlukan suhu pemanasan tertentu. Pada umumnya suhu pemanasan antara $40^{\circ} \mathrm{C}-80^{\circ} \mathrm{C}$, tetapi suhu ini sangat tergantung pada jenis logam yang akan dianalisis. Untuk logam Zn oksida yang terbentuk adalah $\mathrm{ZnO}$ yang cukup stabil pada suhu pengabuan yang digunakan. Oksida-oksida ini kemudian dilarutkan ke dalam pelarut kombinasi asam mineral $\mathrm{HNO}_{3}-\mathrm{H}_{2} \mathrm{SO}_{4}$ (1:1) dan kombinasi asam mineral $\mathrm{HNO}_{3}-\mathrm{HCl}(1: 3)$, setelah itu konsentrasi logam dalam larutan sampel dianalisis menggunakan metode spektrofotometer serapan atom (SSA) (Kristianingrum, 2012).

\section{Digesti dengan kombinasi asam mineral $\mathrm{HNO}_{3-}$ $\mathrm{H}_{2} \mathrm{SO}_{4}(1: 1)$}

Campuran $\mathrm{H}_{2} \mathrm{SO}_{4}$ dan $\mathrm{HNO}_{3}$ pekat banyak digunakan untuk mempercepat proses digesti karena kedua asam ini merupakan oksidator yang kuat. Pada proses ini karena menggunakan larutan $\mathrm{HNO}_{3}$ pekat maka akan terbentuk nitrogen oksida (NO). Dengan adanya NO yang terbentuk memungkinkan terjadinya interferensi pada proses serapan dalam analisis logam. Tetapi interferensi tersebut dapat dihilangkan oleh $\mathrm{H}_{2} \mathrm{SO}_{4}$ dengan dekomposisi asam nitrat ketika proses digesti mencapai suhu tinggi yang ditandai dengan keluarnya asap putih yang merupakan gas $\mathrm{SO}_{2}$ yang menggantikan gas NO (Twyman, 2005).

\section{Digesti dengan kombinasi asam mineral $\mathrm{HNO}_{3-}$ $\mathrm{HCl}(1: 3)$}

Kombinasi asam mineral $\mathrm{HNO}_{3}-\mathrm{HCl}$ disebut juga aqua regia yang mampu melarutkan logamlogam mulia seperti emas dan platina yang tidak larut dalam $\mathrm{HCl}$ pekat dan $\mathrm{HNO}_{3}$ pekat. $\mathrm{HNO}_{3}$ bertindak sebagai agen pengoksidasi sedangkan $\mathrm{HCl}$ memberikan sifat kompleks. Pada proses ini melepaskan gas klorin $\left(\mathrm{Cl}_{2}\right)$ dan gas nitrosil klorida $(\mathrm{NOCl})$ yang mengubah logam menjadi senyawa logam klorida dan selanjutnya diubah menjadi kompleks anion yang stabil yang selanjutnya bereaksi lebih lanjut dengan $\mathrm{Cl}^{-}$(Twyman, 2005).

Hasil pengukuran konsentrasi logam Zn pada masing-masing kombinasi asam mineral dengan menggunakan spektrofotometer serapan atom (SSA) dapat dilihat pada Gambar 1. Untuk kombinasi asam mineral $\mathrm{HNO}_{3}-\mathrm{H}_{2} \mathrm{SO}_{4}$ (1:1), diperoleh konsentrasi logam $\mathrm{Zn}$ dalam berat kering sedimen berkisar antara $244,40-374,75 \mathrm{mg} / \mathrm{kg}$ dan untuk kombinasi asam mineral $\mathrm{HNO}_{3}-\mathrm{HCl}$ (1:3), diperoleh konsentrasi logam $\mathrm{Zn}$ dalam berat kering sedimen berkisar antara 565,05 - 2371,85 $\mathrm{mg} / \mathrm{kg}$.

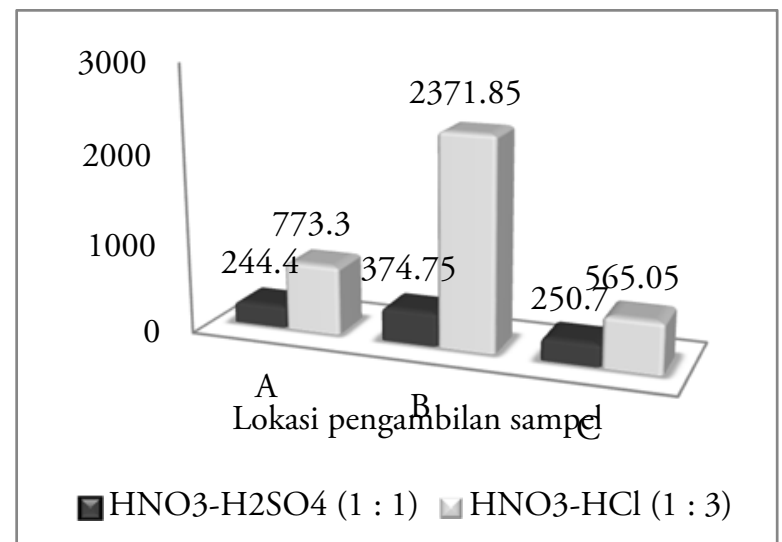

Gambar 1. Diagram distribusi konsentrasi logam Zn pada masing-masing kombinasi asam mineral dari masing-masing lokasi pengambilan sampel 
Diketahui konsentrasi logam Zn pada kedua kombinasi asam mineral tersebut yang paling tinggi terdapat pada lokasi B. Tingginya konsentrasi logam $\mathrm{Zn}$ pada lokasi B karena pada lokasi ini adalah muara sungai yang merupakan titik awal pencampuran antara air tawar dan air laut dengan kandungan lumpur yang lebih tinggi karena terbawa oleh arus sungai dan laut. Disamping itu juga dengan adanya perbedaan tekstur tanah (substrat) pada sedimen merupakan salah satu faktor yang menyebabkan konsentrasi logam Zn pada masing-masing lokasi berbeda. Lumpur mempunyai ukuran sedimen yang halus sehingga mempunyai kemampuan yang baik dalam mengikat logam dalam sedimen, karena partikel sedimen yang halus memiliki luas permukaan yang besar dengan kerapatan ion yang lebih stabil untuk mengikat logam (Maluskah, 2013).

Selain itu, penyebaran logam $\mathrm{Zn}$ tidak merata pada setiap titik lokasi, hal ini sangat bergantung pada aktivitas pendukung keberadaan logam $\mathrm{Zn}$ tersebut. Keberadaan logam $\mathrm{Zn}$ cenderung berasal dari aktivitas di estuaria sungai dan sekitarnya yaitu seperti kawasan pemukiman, rekreasi, aktifitas pelayaran, dan penambangan pasir. Disamping itu, sungai Palu juga digunakan sebagai tempat pembuangan sampah bagi masyarakat sekitar sungai.

Canadian Council of Ministers for the Environment (2002) menetapkan nilai ambang batas logam $\mathrm{Zn}$ dalam sedimen untuk perlindungan kehidupan biota laut adalah 271 $\mathrm{mg} / \mathrm{kg}$. Dengan demikian berdasarkan nilai ambang batas logam $\mathrm{Zn}$ tersebut dapat diasumsikan bahwa kandungan logam $\mathrm{Zn}$ dalam sedimen pada semua lokasi pengambilan sampel sedimen sudah melampaui dari nilai ambang batas konsentrasi logam $\mathrm{Zn}$ yang ada.

Konsentrasi logam $\mathrm{Zn}$ yang diperoleh dari masing-masing hasil pengukuran, ditentukan rataratanya secara statistik sehingga diperoleh nilai rata-rata signifikan logam $\mathrm{Zn}$ untuk kombinasi asam mineral $\mathrm{HNO}_{3}-\mathrm{H}_{2} \mathrm{SO}_{4} \quad(1: 1)$ yaitu $289,95 \pm 182,49 \mathrm{mg} / \mathrm{kg}$. Sedangkan nilairata-rata signifikan logam $\mathrm{Zn}$ untuk kombinasi asam mineral $\mathrm{HNO}_{3}-\mathrm{HCl}(1: 3)$ yaitu $669,18 \pm 447,72$ $\mathrm{mg} / \mathrm{kg}$.

Daya digesti berbagai kombinasi asam mineral ditunjukkan oleh nilai standar deviasi relatif. Nilai standar deviasi relatif untuk kombinasi asam mineral $\mathrm{HNO}_{3}-\mathrm{H}_{2} \mathrm{SO}_{4}(1: 1)$ adalah $25,35 \%$ dan untuk kombinasi asam mineral $\mathrm{HNO}_{3}-\mathrm{HCl}$ (1:3) adalah $22 \%$. Kombinasi asam mineral yang mempunyai nilai standar deviasi relatif yang paling rendah berarti memiliki daya digesti paling tinggi yaitu pada kombinasi asam mineral $\mathrm{HNO}_{3}-\mathrm{HCl}$ (1:3) (Nafie, 1999).

\section{Kesimpulan}

Rata-rata signifikan konsentrasi logam Zn pada dalam sampel sedimen estuaria sungai Palu dengan kombinasi asam mineral $\mathrm{HNO}_{3}-\mathrm{H}_{2} \mathrm{SO}_{4}$ (1:1) adalah $289,95 \pm 182,49 \mathrm{mg} / \mathrm{kg}$ dan rata-rata signifikan konsentrasi logam Zn pada dalam sampel sedimen estuaria sungai Palu dengan kombinasi asam mineral $\mathrm{HNO}_{3}-\mathrm{HCl}$ (1:3) adalah $669,18 \pm 447,72 \mathrm{mg} / \mathrm{kg}$. Kombinasi asam mineral yang memiliki daya digesti paling tinggi terhadap logam $\mathrm{Zn}$ dalam sampel sedimen estuaria sungai Palu adalah kombinasi asam mineral $\mathrm{HNO}_{3}-\mathrm{HCl}$ (1:3).

\section{Ucapan Terima Kasih}

Penulis mengucapkan terima kasih kepada kepala laboran Laboratorium Pendidikan Kimia FKIP Universitas Tadulako dan kepala laboran Laboratorium Kimia Analitik Institut Teknologi Bandung (ITB) serta semua pihak yang telah membantu dalam pelaksanaan penelitian ini.

\section{Referensi}

Andrean. (2012). Analisis sampel batubara dari Sumatera Selatan. Bogor: Institut Pertanian Bogor.

Canadian Council of Ministers for the Environment, (CCME). (2002). Canadian sediment quality guidelines for the protection of aquatic life: Summary tables. http://www.popstoolkit.com/Tools/SitePrioriti zation/Files/Guidelines/SedQ\%20aquatic\%201 ife.pdf.

Darmono. (2008). Lingkungan hidup dan pencemaran: Hubungannya dengan toksikologi senyawa logam. Jakarta: UI Press.

Edward. (2014). Kandungan logam berat dalam sedimen di perairan Teluk Wawobatu, Kendari, Sulawesi Tenggara. Jurnal Depik, 3(2), 157-165.

Fismawati. (2010). Analisis logam berat Krom (Cr) dan Timbal (Pb) dalam sedimen muara sungai Palu. Universitas Tadulako.

Khopkar, S. M. (1990). Konsep dasar kimia analitik (A. Saptoharjo Ed.). Jakarta: UI Press.

Kristianingrum, S. (2012). Kajian berbagai proses destruksi sampel dan efeknya. Paper presented at the Prosiding Seminar Nasional Penelitian, Pendidikan dan Penerapan MIPA, Fakultas MIPA, Universitas Negeri Yogyakarta.

Maluskah, L. (2013). Hubungan antara konsentrasi logam berat $\mathrm{Pb}, \mathrm{Cd}, \mathrm{Cu}, \mathrm{Zn}$ dengan bahan organik dan ukuran butir dalam 
sedimen di estuaria banjir Kanal Barat, Semarang. Buletin Oseanografi Marina, 2, 5562.

Nafie, N. L., Wahab, A. W. \& Malik, A. (1999). Ekstraksi logam berat $\mathrm{Cd}$ dan $\mathrm{Cu}$ dalam sedimen laut dangkal dengan beberapa kombinasi asam mineral. Marina Chimica Acta, Edisi Spesial, 12-15.

Öztürk, M., Özözen, G., Minareci, O. \& Minareci, E. (2009). Determination of heavy metals in fish, water and sediments of Avsar Dam Lake in Turkey. Iranian Journal of Environmental Health Science and Engineering, 6(2), 73-80.
Ratnasari, G. A. H. K., Siaka, I. M. \& Suastuti, N. G. A. M. D. A. (2013). Kandungan logam total $\mathrm{Pb}$ dan $\mathrm{Cu}$ pada sayuran dari sentra hortikultura daerah Bedugul. Jurnal Kimia, $7(2), 127-132$.

Sarjono, A. (2009). Analisis kandungan logam berat $\mathrm{Cd}, \mathrm{Pb}$ dan $\mathrm{Hg}$ pada air dan sedimen di perairan Kamal Muara Jakarta Utara. Bogor: Institut Pertanian Bogor.

Twyman, R. M. (2005). Wet diggestion: Sample dissolution for elemental analysis. University of York: Elsevier Ltd. 